\title{
Prevalence and awareness of hypertension among Sudanese rural population, Sinnar State, Sudan, 2016
}

\author{
Badria A. Elfaki ${ }^{* 1}$, Hassanat E. Mustafa ${ }^{2}$, Mustafa K. Elnimeiri ${ }^{3}$ \\ ${ }^{1}$ Department of Nursing Practice, Faculty of Nursing, Um Al-Qura University, Makkah, Sudan \\ ${ }^{2}$ Department of Nursing Practice, Faculty of Nursing, Al Neelain University, Khartoum, Sudan \\ ${ }^{3}$ Faculty of Medicine and Health Sciences, Al-Neelain University, Khartoum, Sudan
}

Received: September 4, 2016

DOI: $10.5430 /$ jnep.v7n6p1
Accepted: December 9, $2016 \quad$ Online Published: January 3, 2017

URL: http://dx.doi.org/10.5430/jnep.v7n6p1

\begin{abstract}
Objective: The aim of this study to estimate the prevalence of hypertension and determine awareness among rural population. Methods: Cross-sectional community based study, conducted in rural community. Population was the resident citizens in age of 25-64 years. A cluster sampling technique was used and total sample size mounted to 341 subjects. The collected data was cleaned, edited and analyzed using SPSS program.

Results: Prevalence of hypertension was $21.1 \%$, systolic was $5.9 \%$ and diastolic hypertension was $10.0 \%$ with no significant differences among gender ( $p$-value .409 ). About $59.7 \%$ of hypertensive subjects were unaware with their diagnosis, men were more awareness than women with proportion of $62.0 \%$ in men and $38.0 \%$ in women. Awareness with hypertension diagnosed was increased by increasing age, income and education. Most of known hypertensive subjects (86.20\%) were on treatment. Approximately $80 \%$ of known hypertensive subjects were complained of signs and symptoms and $31.0 \%$ with complications. Also controlled blood pressure was $34.0 \%$ with proportion of $36.4 \%$ among women and $33.3 \%$ among men.

Conclusions: The study reflected high prevalence of hypertension, systolic and diastolic among rural population, also the level of awareness among hypertensive subjects generally was low; however the level of awareness among elder, educated was better and females were more control hypertension.
\end{abstract}

Key Words: Awareness, Prevalence, Hypertension, Rural, Community

\section{INTRODUCTION}

Globally there are a one billion hypertensive people and four million people die annually with hypertension. ${ }^{[1]}$ Hypertension is the third leading cause of death in the world. ${ }^{[1]}$ Hypertension defined as a persistent or intermittent elevation of systolic blood pressure above $140 \mathrm{mmHg}$ and diastolic blood pressure above $90 \mathrm{mmHg}$ or both, over a sustained period. ${ }^{[2-4]}$ Hypertension is a silent killer problem. ${ }^{[4,5]}$ Early screening and management can prevent or reduced its risk and complications. ${ }^{[6]}$

The current prevalence of hypertension in developing countries particularly an urban societies is already high than in developed countries. ${ }^{[7]}$ The World Hypertension League (WHL), an umbrella organization of 85 national hypertension societies and leagues, recognized more than $50 \%$ of hypertensive populations worldwide were unaware of their hypertension. ${ }^{[8]}$ Most studies were confirmed that hypertension increased cardiovascular risk among population. ${ }^{[9]}$

\footnotetext{
*Correspondence: Badria A. Elfaki; Email: elfakibadria@yahoo.com; Address: Department of Nursing Practice, Faculty of Nursing, Um Al-Qura University, Makkah, Sudan.
} 
Also large population based cohort studies consistently show continuous, strong, and graded relations between blood pressure and the subsequent occurrence of various atherosclerotic events. ${ }^{[9]}$ World Health Organization report 2004, about 600 million people with hypertension are at risk of heart attack, stroke and cardiac failure and found about $62 \%$ of strokes and $49 \%$ of heart attacks are caused by hypertension. ${ }^{[10]}$

Among major non-communicable diseases in Sudan, hypertension has a highest prevalence $(23.6 \%)$ in Khartoum state $^{[6]}$ and it account to $1.3 \%$ of outpatient visits; it was represented as one of 10 leading diseases treated in health facilities and also as one of 10 leading causes of death in $\mathrm{Su}-$ dan6.Previous studies in Sudan documented and published on prevalence and awareness of hypertension in an urban residence population corresponding figures of $7.5 \%$ in 1985 to $18.2 \%$ in $2002,{ }^{[11]} 27.0 \%$ in $2005^{[12]}$ to more recently prevalence $(19.3 \%)$ in Juba South Sudan $2012^{[13]}$ but a few epidemiological studies in rural population was documented.

Role of nursing in preventing hypertension to measure blood pressure and raise wariness; hence it has a significant reduction in its morbidity and mortality so hypertension becoming more prevalent health condition in the world. ${ }^{[14]}$

Objective: The objective of the study was to estimate prevalence rates of hypertension and determine awareness with hypertension so as to enhance awareness of people about prevention, early diagnosis, management and lifestyle changes to reduce and prevent hypertension mortality and morbidity.

\section{Methods}

\subsection{Study design}

A cross-sectional (quantitative) community based study.

\subsection{Study area}

The study was conducted in a rural community in Alsakania town, Sinnar State. It is accommodation of workers and employees families of West Sinnar Sugar Factory.

\subsection{Study population}

Resident citizens; composed of different ethnic groups with diversity of socio-cultural contexts and beliefs. A total population as estimated in last census 2010 amounted to 2,170 inhabitants, resident in 390 housing units. The entire inhabitants were received same services from the Sugar Factory to support their income and facilitate their life.

\subsection{Sample Size}

Desirable sample size of the study was 338 participants, calculated based on standard formula: ${ }^{[15]}$

$\mathrm{n}=\mathrm{N} /\left(1+\mathrm{N}^{*} \mathrm{D}^{2}\right) ; \mathrm{n}$ : is the desirable sample size; $\mathrm{N}$ : is the population size (universe). D: is the degree of accuracy desired (or the accepted margin of error and is usually set to 0.05 . $\mathrm{n}=2170 /[1+2170(0.05 \times 0.05)]=338$ participants (Available sample size amounted to 341 subjects).

\subsection{Sampling technique}

A probability a cluster sampling technique was adopted to draw study sample. Clusters were identified and every member of the cluster was a part of the study. ${ }^{[16]}$ Sample size was distributed over all study area. The area was divided geographically into clusters for verifying boundaries of the sample area in order to ensure a good coverage of the sample households. Total households were divided by a number of households in each cluster; 390/25 = 16 cluster. Sample size was divided by number of households in each cluster to determine the number of clusters to cover the sample; 338/25 $=14$ cluster. A listing of clusters was undertaken in sample prior to data collection in order to enumerate all households within boundaries of the study sample. ${ }^{[1]}$ Clusters samples were selected with simple random sampling technique and only two clusters were excluded from the sample (a total of 16 clusters). The entire elements from each of selected clusters were used (14 cluster).

\subsection{Data collection tools}

Data were collected by standardized structured questionnaire with closed-end questions. A questionnaire was included two sections. Section one was included questions about personal back ground data; such gender, age, educational level and total income per month. Section two questions about hypertension awareness which included questions about awareness with hypertension diagnosed occurred of signs and symptoms, complications, prescribed medication, and checklist for the blood pressure measured.

\subsection{Data collection technique}

Data was collected by senior nurses, after trained to administer questionnaire and measured blood pressure. Entire participants were undergone standard interviewed for data obtained and recorded. A sample of 341 participants was collected from 14 cluster. The survey was completed in a period of one month (morning to evening) in June, year 2013. If inhabitants were not at home at time of visit next visit was conducted. If inhabitants were not found again they were concealed. All available members in the house at time of survey according to inclusion criteria were interviewed and written consent was obtained from entire participants who were enrolled in the study before interviewed them and blood pressure was measured for entire participants at the end of interviewed. 


\subsection{Inclusion criteria}

The study was included both gender; men and women resident permanently in the study area, their age between 25-64 years, both hypertensive and non-hypertensive subjects.

\subsection{Exclusion criteria}

The study was excluded subjects with age less than 25 years, visitors and pregnant ladies.

\subsection{Study variables}

Study variables were included background data, such as gender, age, educational level and total income per month. Awareness with hypertension diagnosed, experience signs and symptoms, complications, prescribed medications and measuring blood pressure to estimate the prevalence rate of hypertension.

\subsection{Definition of awareness}

Awareness about hypertension defined as followed; awareness with hypertension diagnosed means subjects were previously told by their health care provider that they have had hypertension or currently on antihypertensive treatment. Also awareness means subjects were aware with their treatment, occurrence of signs and symptoms, complications and control.

\subsection{Criteria for measuring blood pressure}

Blood pressure was measured used standardized protocol; standardization was included selection of quality blood pressure measuring and proper maintenance of equipment to emphasize accuracy. ${ }^{[2]}$ Blood pressure was measured according to recommendations of Seven Reports of Joint National Committee (JNC) on Prevention, Detection, Evaluation and Treatment of high blood pressure. ${ }^{[18]}$ The subject was seated quietly on a chair for at least 5 minutes with feet on the floor, arm supported at the heart level. Subject was refined from caffeine, exercise, and smoking for at least 30 minutes prior to measurement. ${ }^{[18]}$ An appropriately sized cuff encircling at least 80 percent of the arm was used to ensure accuracy of measurement. The cuff was inflated $30 \mathrm{mmHg}$ above this level for auscultatory determinations; the cuff deflation rate for auscultatory readings was $2 \mathrm{mmHg}$ per second. ${ }^{[18]}$ Both systolic blood pressure (SBP) and diastolic blood pressure (DBP) were recorded. ${ }^{[18]}$ The first appearance of sound (phase 1) was used to define SBP, disappearance of sound (phase 5) was used to define DBP, two measurements were done and average of blood pressure was made. ${ }^{[18]}$ Subject was labeled as hypertensive if their blood pressure $>140 / 90$ $\mathrm{mmHg}$ or participants said they were taking antihypertensive medications. ${ }^{[19]}$ The data collection team were explained to participants their blood pressure reading and importance of regular checking and measuring blood pressure in those who labeled elevated in blood pressure.

\subsection{Pre-test of the instruments}

Questionnaire and equipment which used for collection studied subjects' data were tested. Questionnaire was pre-tested before used in fifteen subjects; then it was modified and a few questions were adjusted to ensure reliability and accuracy of the questionnaire.

\subsection{Equipment which used for measuring blood pres- sure}

Mercury sphygmomanometer and stethoscope were checked for functioning. Mercury sphygmomanometer calibrated with a good quality electronic reference manometer. ${ }^{[2]}$ The diaphragm of the stethoscope was used to hear sounds of blood pressure and the earpieces on the stethoscope were pointed forward and fit perfectly on ears. ${ }^{[2]}$ To eliminate the errors in the measurements, blood pressure was made in three persons by reference sphygmomanometer and compared with the reading of the sphygmomanometers that was intended to use in the survey.

\subsection{Data analysis}

The analysis of data was done using computer package program version 16.0 after pre-coded, pre-tested and cleaned. Suitable descriptive statistic was used and data analysis was included both Univariate and Bivariate analysis. ${ }^{[20]}$ Univariate analysis was carried out to describe a single variable such as socio-demographic factors and Bivariate analysis involves analysis of two variables for purpose of determining relationship between them such as, the prevalence and awareness of hypertension versus socio-demographic factors and data was presented in form of a percentage table. ${ }^{[21]}$ Prevalence of hypertension was estimated as the percentage of participants' classified hypertensive as the numerator, with all study participants as the denominator. ${ }^{[22]}$ The $t$-test for independent samples was used to compare mean systolic and diastolic blood pressure among hypertensive and normal subjects regarding to their gender. Fisher test and chi-square were used to compare variables and data was summarized as mean and standard deviation (SD). ${ }^{[23]}$

\subsection{Ethical considerations}

The study was approved by an ethical clearance from Institutional Review Board of Al-Neelain University, agreement from Alsakania Town Popular Committee and informed written consent from entire participants before obtained interviewed. 


\section{RESUlts}

Figure 1 showed over all prevalence of hypertension among studied subject was found $(21.10 \%)$ and prevalence of sys- tolic hypertension $\geq 140 \mathrm{mmHg}$ and diastolic hypertension $\geq 90 \mathrm{mmHg}$ was $(10.60 \%)$ and $(8.80 \%)$ respectively.

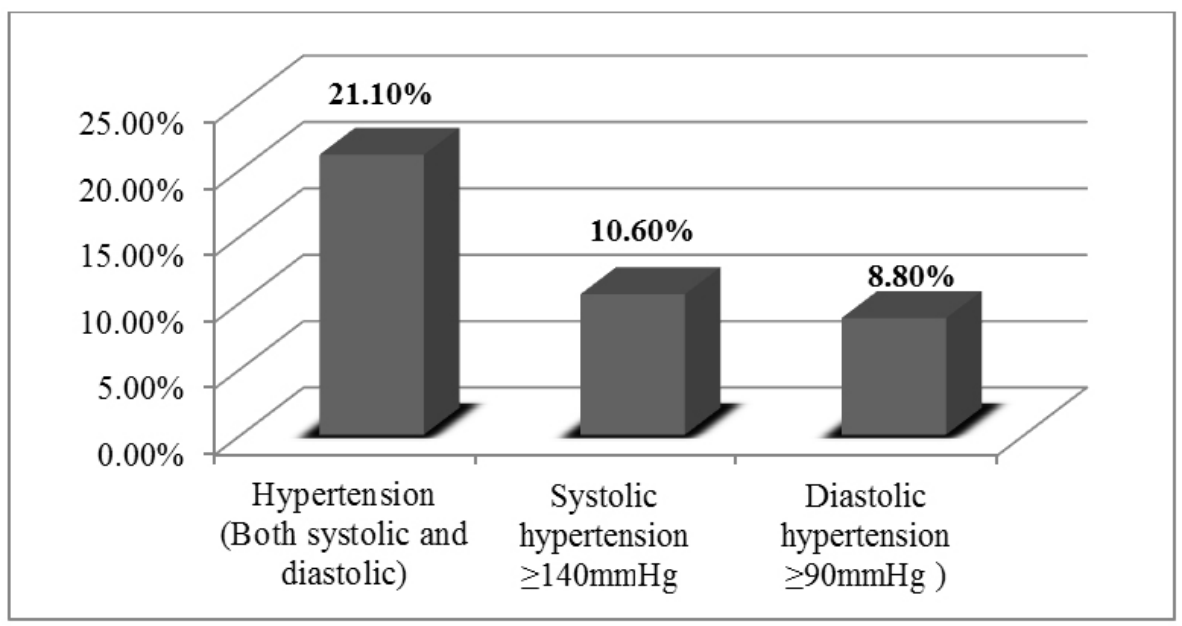

Figure 1. Prevalence of hypertension, systolic, and diastolic hypertension among the study population $(\mathrm{n}=341)$

Table 1 showed the prevalence of hypertension was $21.10 \%$ with no difference among gender, systolic hypertension was high among females than males with proportion of $12.4 \%$ and $8.5 \%$ respectively and males have had a higher prevalence of diastolic hypertension than females with proportion of $9.8 \%$ among males and $7.9 \%$ among females, this insignificances $(p$-value $>.001)$.

Table 1. Prevalence of hypertension, systolic and diastolic hypertension in relation to gender $(n=341)$

\begin{tabular}{lllll}
\hline \multirow{2}{*}{ Hypertension } & Gender & & \multirow{2}{*}{ Total } & $\boldsymbol{p}$-value \\
\cline { 2 - 4 } & Male & Female & & .409 \\
Hypertension (both systolic \& diastolic) & $21.3 \%$ & $20.9 \%$ & $21.1 \%$ & .242 \\
Systolic hypertension $\geq 140 \mathrm{mmHg}$ & $8.5 \%$ & $12.4 \%$ & $10.6 \%$ & .548 \\
Diastolic hypertension $\geq 90 \mathrm{mmHg}$ & $9.8 \%$ & $7.9 \%$ & $8.8 \%$ & \\
\hline
\end{tabular}

Hypertensive subjects approximately have had a same mean systolic and diastolic blood pressure. The mean systolic blood pressures was $141.71 \mathrm{mmHg} \pm(\mathrm{SD} 9.231)$ in males and $142.03 \mathrm{mmHg} \pm(\mathrm{SD} 9.388)$ in females, and the mean diastolic blood pressures was $91.29 \mathrm{mmHg} \pm(\mathrm{SD} 8.344)$ in males and $90.81 \mathrm{mmHg} \pm(\mathrm{SD} 8.038)$ in females. On the other hand normotensive subjects have had higher significant differences in their mean systolic and diastolic blood pressure regarded their gender. Mean systolic blood pressure in males and females were $122.24 \mathrm{mmHg} \pm$ (SD 7.686) and $116.62 \mathrm{mmHg} \pm(\mathrm{SD} 10.363)$ respectively, and the mean diastolic blood pressure was $78.41 \mathrm{mmHg} \pm$ (SD 4.688) and $74.72 \mathrm{mmHg} \pm(\mathrm{SD} 7.514)$ respectively (see Table 2$)$.

Table 3 showed a higher significance prevalence $(32.0 \%)$ of hypertension was found among age group of 45-54 year ( $p$ value $<.001)$. Also showed insignificance high prevalence of systolic hypertension among this age group (16.4\%) and insignificance high prevalence (11.9\%) of diastolic hypertension was found among the study subjects in age group of 55-64 year ( $p$-value $>.001)$.

Figure 2 showed $59.7 \%$ of diagnosed hypertensive by the study, were unaware with their hypertension only $40.30 \%$ they were aware and known they have had hypertension.

Among known hypertensive subjects males were more awareness with their hypertension diagnosed than females with proportion of $62.1 \%$ among males and $37.9 \%$ among females. Subjects in the middle age (45-54 years) awareness about their hypertension diagnosed was $55.2 \%$, secondary school education was more aware with their hypertension diagnosed than the other education levels with proportion of $62.1 \%$ followed by university and post education (20.7) and lower awareness $(6.9 \%)$ were found among illiterate ( $p$-value <.005). Also, hypertension was insignificant diag- 
nosed among subjects with moderate income (39.9\%) and and high income (see Table 4).

same proportion $(27.6 \%$ ) was found among subjects with no

Table 2. Mean systolic and diastolic blood pressure among study subjects in relation to gender $(\mathrm{n}=341)$

\begin{tabular}{|c|c|c|c|c|c|c|c|}
\hline Blood pressure & & $\mathbf{N}$ & Mean & Std. Deviation & Std. Error & $\mathbf{F}$ & $p$-value \\
\hline \multicolumn{8}{|l|}{ Hypertensive subjects } \\
\hline \multirow{2}{*}{ Systolic blood pressure } & Male & 35 & 141.71 & 9.231 & 1.560 & \multirow{2}{*}{.020} & \multirow{2}{*}{.889} \\
\hline & Female & 37 & 142.03 & 9.388 & 1.543 & & \\
\hline \multirow{2}{*}{ Diastolic blood pressure } & Male & 35 & 91.29 & 8.344 & 1.410 & \multirow{2}{*}{1.383} & \multirow{2}{*}{.244} \\
\hline & Female & 37 & 90.81 & 8.038 & 1.321 & & \\
\hline \multicolumn{8}{|l|}{ Normotensive subjects } \\
\hline \multirow{2}{*}{ Systolic blood pressure } & Male & 107 & 122.24 & 7.686 & .743 & \multirow{2}{*}{14.876} & \multirow{2}{*}{.000} \\
\hline & Female & 108 & 116.62 & 10.363 & .997 & & \\
\hline \multirow{2}{*}{ Diastolic blood pressure } & Male & 107 & 78.41 & 4.688 & .453 & \multirow{2}{*}{48.314} & \multirow{2}{*}{.000} \\
\hline & Female & 108 & 74.72 & 7.514 & .723 & & \\
\hline
\end{tabular}

Table 3. Prevalence of hypertension, systolic and diastolic hypertension in relation to age groups $(\mathrm{n}=341)$

\begin{tabular}{lllllll}
\hline \multirow{2}{*}{ Hypertension } & \multicolumn{2}{l}{ Age groups in years } & \multicolumn{3}{c}{ Total } & \multirow{2}{*}{$\boldsymbol{p}$-value } \\
\cline { 2 - 6 } & $\mathbf{2 5 - 3 4}$ & $\mathbf{3 5 - 4 4}$ & $\mathbf{4 5 - 5 4}$ & $\mathbf{5 5 - 6 4}$ & & \\
\hline Hypertension (both systolic \& diastolic) & $11.2 \%$ & $16.2 \%$ & $32.0 \%$ & $18.6 \%$ & $21.1 \%$ & .000 \\
Systolic hypertension $\geq \mathbf{1 4 0} \mathbf{m m H g}$ & $5.0 \%$ & $5.0 \%$ & $16.4 \%$ & $13.6 \%$ & $10.6 \%$ & .017 \\
Diastolic hypertension $\geq \mathbf{9 0} \mathbf{~ m m H g}$ & $8.8 \%$ & $6.2 \%$ & $9.0 \%$ & $11.9 \%$ & $8.8 \%$ & .718 \\
\hline
\end{tabular}

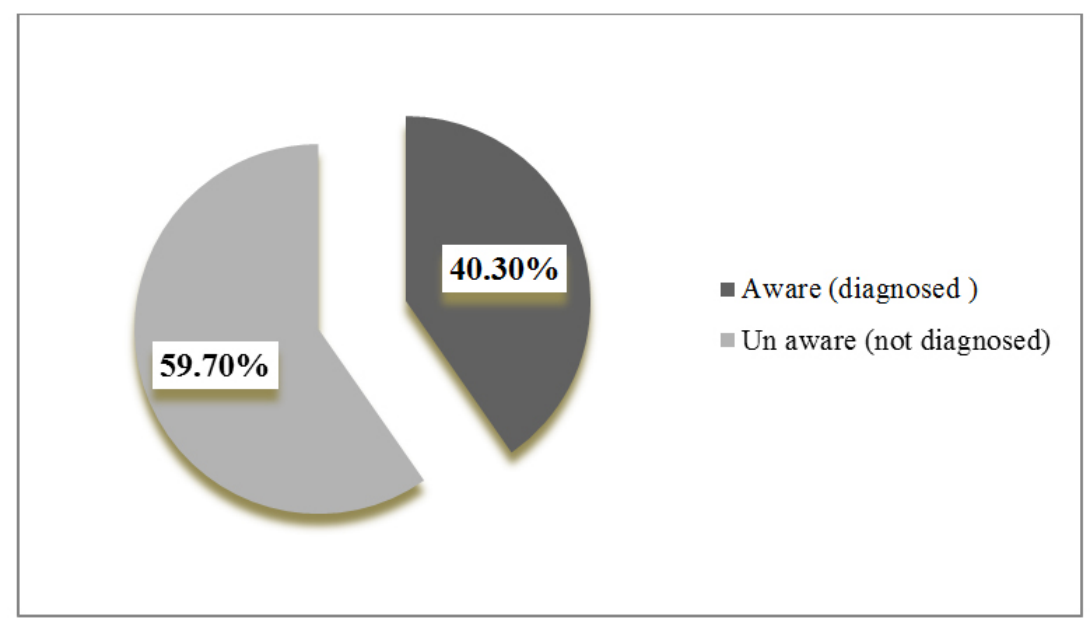

Figure 2. Awareness of hypertensive subjects with their diagnosed $(n=72)$

Table 5 showed $(79.30 \%)$ of known hypertensive subjects were complained of hypertension signs and symptoms. Headache was more occurred with proportion of $69.0 \%$, followed by fatigue or weakness $(48.3 \%)$, dizziness and blurred vision were occurred with the same proportion (6.9\%), and no other signs were occurred. About $31.0 \%$ of known hypertensive subjects were complained of complications, while $69.0 \%$ were no complications. Heart attack was highly occurred with proportion of $(17.20 \%)$, followed by Stroke Published by Sciedu Press
(10.30\%) which had same occurrence as the kidney diseases and vision disturbance was occurred in low percent. Most of known hypertensive subjects $(86.20 \%)$ were on treatment, while $13.80 \%$ they weren't received any. About $60 \%$ of hypertensive subjects were one drug while $40.0 \%$ were on two drugs and there were no any subject on three or more drugs. Known hypertensive subject with normal blood pressure was $36.4 \%$ among female and $33.3 \%$ among male. 
Table 4. Awareness of known hypertensive subjects with their hypertension diagnosed versus socio-demographic factors (n

\begin{tabular}{llll}
\hline Hypertension diagnosed & & & \\
\hline \multirow{3}{*}{ Gender } & Male & Percentage (\%) & -Value \\
& Female & 62.1 & .194 \\
& Total & 37.9 & \\
Age groups & 25-34years & 100.0 & \\
& 35-44years & 10.3 & .002 \\
& 45-54years & 13.8 & \\
& 55-64years & 55.2 & \\
Education level & Total & 20.7 & .000 \\
& Illiterate & 100.0 & \\
& Primary/basic school & 6.9 & \\
& Secondary school & 10.3 & \\
& University+ & 62.1 & .117 \\
& Total & 20.7 & \\
Monthly income & No income & 100.0 & \\
& low income & 27.6 & \\
& Moderate income & 6.9 & \\
& High income & 27.9 & \\
& Total & 100.0 &
\end{tabular}

Table 5. Awareness of known hypertensive subjects with their hypertension signs and symptoms, medication, complications and control blood pressure $(\mathrm{n}=29)$.

\begin{tabular}{|c|c|c|}
\hline Item & & Percentage (\%) \\
\hline \multirow{2}{*}{ Signs and symptoms } & Yes & 20.70 \\
\hline & No & 79.30 \\
\hline \multirow{4}{*}{ Common signs and symptoms } & Headache & 60.0 \\
\hline & Fatigue & 48.3 \\
\hline & Dizziness & 6.90 \\
\hline & Blurred vision & 6.90 \\
\hline \multirow{2}{*}{ Complications } & Yes & 31 \\
\hline & No & 69 \\
\hline \multirow{2}{*}{ Complications among gender } & Male & 22.2 \\
\hline & Female & 45.5 \\
\hline \multirow{4}{*}{ Common complications } & Heart attack & 17.2 \\
\hline & Stroke & 10.30 \\
\hline & Kidney & 10.30 \\
\hline & Vision disturbance & 3.40 \\
\hline \multirow{2}{*}{ On medications } & Yes & 86.20 \\
\hline & No & 13.80 \\
\hline \multirow{3}{*}{$\begin{array}{l}\text { Number of prescribed } \\
\text { medications }\end{array}$} & One & 60.00 \\
\hline & Two & 40.00 \\
\hline & Three & 0 \\
\hline \multirow{2}{*}{$\begin{array}{l}\text { known hypertensive subjects } \\
\text { with control blood pressure }\end{array}$} & Male & 33.3 \\
\hline & Female & 36.4 \\
\hline
\end{tabular}

\section{Discussion}

Hypertension is an increasingly important medical and public health issue. ${ }^{[24]}$ Prevalence of hypertension in our sample was $21.10 \%$ with no difference among gender. The levels of blood pressure were based on the average of 2 measurements at a single visit, and the prevalence was estimated based on its definition. Nonetheless, this documented a lower prevalence than other studies, a previous study in rural Uganda 2009 estimated prevalence of $30.4 \% .{ }^{[25]}$ Also the study documented lowered prevalence than reported by National Health and Morbidity Survey 1996 which was showed prevalence of $33 \%$ or an estimated 2.6 million among Malaysian adults aged 30 or older, ${ }^{[26]}$ and higher than that estimated 2009 (17.3\%) in Iranian population. ${ }^{[27]}$ Also, prevalence of systolic hypertension $\geq 140 \mathrm{mmHg}$ and diastolic hypertension $\geq 90 \mathrm{mmHg}$ was respectively $10.60 \%$ and $8.80 \%$ (see Figure 1). This is lower than prevalence estimated by study in the same rural community conducted in India to investigate prevalence of hypertension among age group of 30 years and above which documented prevalence of $18.5 \%-15 \%$ systolic and diastolic respectively. ${ }^{[28]}$ The studied found females have had a higher systolic blood pressure than males, who have a higher diastolic blood pressure. Statistically no difference was observed between gender regarding the prevalence of systolic and diastolic hypertension (see Table 1). This is sim- 
ilar to India study ${ }^{[28]}$ and higher than that estimated from the population based study on prevalence of hypertension among adults in Addis in which systolic and diastolic blood pressure in males were $8.9 \%, 8.3 \%$ and in females were $5.8 \%, 6.0 \%$ respectively. ${ }^{[29]}$

Hypertensive subjects have had a same mean systolic and diastolic blood pressure with no significance difference among males and females. On the other hand normotensive subjects have highly significant differences in mean systolic and diastolic blood pressures regarded their gender as indicated by fissure test and $p$-value (see Table 2). Normotensive males have a higher mean systolic and diastolic blood pressure than females, this support the finding of Malaysian study ${ }^{[26]}$ and greater than that reported in rural Uganda 2009. ${ }^{[25]}$

As the people aging, the incidence of hypertension increases. Therefore, we can expect to see more cases of hypertension as the population ages and life span increases. ${ }^{[4]}$ This study supported the evidence that hypertension was increased as age increased. A higher significance prevalence of hypertension $(32.0 \%)$ was observed among age group of 45-54 years $p$-value <.001 (see Table 3). Hypertension was increased with age this is similar to previous study. ${ }^{[30]}$ Age-related hypertension appears to be predominantly systolic rather than diastolic. The systolic blood pressure rises into the eighth or ninth decade, whereas the diastolic blood pressure remains constant or declines after age 40 years. The third NHANES survey reported that prevalence of hypertension grows significantly with increasing age in all sex and race groups. ${ }^{[31]}$ Our study showed high prevalence (16.4\%) of systolic hypertension among the subjects in age group of 45-54 years (see Table 3). This means hypertension started to increase with age, then at the age of 55-64 year started to decrease and the diastolic hypertension was high among this age group, this is against the literature, the fact that systolic hypertension was increased as age was increased.

Among hypertensive population, only (40.3\%) are aware with their hypertension diagnosed; they were told by their doctors and health care providers that they were get hypertension or currently on antihypertensive treatment (see Figure 2). This result disagrees with the previous study in urban Khartoum $^{[11]}$ and Trivandrum City of Kerala (South India) ${ }^{[32]}$ and high awareness than that detected in Kuwait. ${ }^{[33]}$ Males were more awareness than females and this is not similar to that reported by a previous systemic review. ${ }^{[34]}$ Awareness with hypertension diagnosed is increased with the age. This study reflects the people in middle age (45-54 years) were more aware with their hypertension diagnosed than the young and old age. Education had significant influenced in awareness of the subjects with their hypertension diagnosed. Secondary

Published by Sciedu Press school education was more aware with their hypertension diagnosed than others education levels followed by university and post education, and lower awareness was found among illiterate " $p$-value $<.005$ ". This is similar to Trivandrum City of Kerala (South India) study. ${ }^{[32]}$ Hypertension was insignificantly diagnosed among subjects with moderate income same awareness was found among subjects with no and high income. The awareness with hypertension diagnosed was increased with income, this study was showed inverse result, this is seem to be because of that, entire subjects were dependent to free health services in this rural community (see Table 4).

Approximately eighty percent of known hypertensive subjects were complained of hypertension signs; remaining (20.7\%) were silent. Headache was more occurred followed by fatigue or weakness, dizziness and blurred vision similar were occurred and no other signs were found (see Table 5). Approximately thirty percent of known hypertensive subjects were complained of complications, while the rest were remained free, a result which is similar to study in Kassala, Eastern Sudan to assess drug compliance among hypertensive patients. ${ }^{[35]}$ In spite of females had more complications occurred than males, females have had control blood pressure than males. Heart attack was highly occurred with proportion followed by stroke and kidney diseases which were same occurrence, and vision disturbance was occurred in low percent (see Table 5). Most of known hypertensive subjects $(86.20 \%)$ were on treatment, while $13.80 \%$ they weren't received any. Comparing with an urban study in Sudan this study documented high rate of treatment in rural than reported in urban11. Sixty percent of known hypertensive subjects were on mono-therapy while forty percent were on two drugs and there was no any subject on three or more drugs. ${ }^{[36]}$ Known hypertensive subject with control pressure was $36.4 \%$ among females and $33.3 \%$ among males (see Table 5). This means women have greater normal blood pressure than men. This indicates a need for increased efforts from health care professionals to manage and treat hypertension successfully. ${ }^{[5]}$

\section{LiMITATIONS}

Hypertension was diagnosed based on two blood pressures measurement from only one visit to the subject house.

\section{Conclusion}

The study documented that high prevalence rate of hypertension among Sudanese rural community with no significant differences among gender, also the level of awareness among hypertensive cases generally was low, but the level of awareness among elder, educated was better. Most of 
known hypertensive subjects were compliant on treatment and women were more control also most common symptom was a headache and heart attack was more occurrence complication among known hypertensive subjects.

\section{RECOMMENDATIONS}

The study recommended, public health measures are necessary to increase awareness, treatment and control of hypertension, health education should be stresses to improve population knowledge about hypertension and its sequels, improvement of awareness for hypertension and early detection and treatment of high blood pressure in the community may reduce the risk of developed complications and need for urgent medical and social intervention. Also, there is a need to increase awareness of primary health care doctors towards importance of opportunistic screening, for early detection of undiagnosed hypertensive individuals.

\section{ACKNOWLEDGEMENTS}

Our thanks extended to Al-Neelain University, Sudan and Umm Al-Qura University for their moral and unlimited support. Also our thanks extend to people of Alsakania town for their facilitation and kind hospitality during the field work.

\section{CONFlicts OF InTEREST Disclosure}

The authors declare that there is no conflict of interest.

\section{REFERENCES}

[1] Sudan Society of Hypertension (SSH). Non-Communicable Diseases Directorate Federal Ministry of Health, Sudan Hypertension Guideline: 2012. Available from: http://ssh-sd.org/fileload/sud an $\% 20$ hypertension $\% 20$ guidelines.pdf

[2] UTAH Department of Health. Heart Disease and Stroke Prevention Program, Adult Blood Pressure Measurement Standardization protocol. 801-538-6141. review July 2006; 1-22. Available from: http: //www . wellnessproposals. com/health-care/handouts/b lood-pressure/adult-blood-pressure-manual.pdf

[3] Suzanne C, Brenda G. Buruner and Suddarths Tex book of Medical Surgical nursing: 9th ed. Lippincott; 717-1064.

[4] Linda SW, Paula Dh. Understanding Medical Surgical Nursing: 3th ed. F.A. Davis Company, Philadelphia; 2007. 374-486.

[5] Susan LW, et al. Cardiac Nursing: 4th ed. Williams \& Wilkins press, Lippincott.

[6] Sudan Hypertension Guideline. Federal Ministry of Health in collaboration with: Sudan Hypertension Society. Non-Communicable Diseases Directorate Federal Ministry of Health, Sudan Hypertension Guideline: 2011

[7] World Health Organization, International Society of Hypertension. Writing group, Statement on management of hypertension. Journal of hypertension. 2003; 21(11): 1983-87. Available from: http/www. who. Int/cardiovasculardisease/guideli nes/hypertension.guidelines-pdf

[8] Wikipedia, the free encyclopedia. Arterial Hypertension. Available from: http://en.wikipedia.org/wiki/Hypertension

[9] Raj P, et al. Evidence based management of hypertension. Cardiovascular risk factors and their effects on the decision to treat hypertension: evidence based review. Available from: http://www.ncbi .nlm.nih.gov/pmc/articles/PMC1120139/pdf/977.pdf Accessed on: 24/5/2015.

[10] National Hypertension Associations. International Cardiovascular Disease Statistics. Available from: http://www . apha.org/wfpha /about_wfpha.htm Accessed May 23, 2010.

[11] Soumeya MS, et al. Prevalence of Hypertension in An urban Community in Sudan. Khartoum Medical Journal. 2008; 72-74. Available from: http://www.meduofk.net/volNo2/prevalence_ hypertension.pdf

[12] Abu-Asha H, et al. Hypertension and Obesity in Police Forces House Hold in Khartoum, Sudan. Sudanese Journal of Public Health. 2008;
3(1): 17-25. Available from: http://www.google.com/search? $\mathrm{hI}=$ en $89=$ sudanese + journal + forbublicthealth + research +inthypertention\&btng=search

[13] Wakea R, Mazindab C. Hypertension in Juba, South Sudan. South Sudan Medical Journal. SSMJ. 2013. Available from: http://www. southsudanmedicaljournal. com Accessed March 22, 2013.

[14] Kofi J. Prevention and Management of Hypertension: A study on knowledge and attitudes of women of childbearing age. September 2011. Available from: http://publications.theseus.fi/bitstream/handle /10024/41325/Kofi_Janet\%20pdf .pdf?sequence=1

[15] Israel GD. Determining Sample Size. 2009.

[16] World Health Organization. Health Research Methodology, A Guide for Training in Research Methods: 2nd ed. Regional Office for the Western Pacific Manila. 2011. 75-128. Available from: http://www . wpro. who.int/publications/docs/Hea lth_research_edited.pdf Accessed April 21, 2012.

[17] National Ministry of Health Government of Southern Sudan and Southern Sudan Commission for census, Statistics an Evolution 2006. Sudan House Hold Health Survey. WHO web site. Available from: http://www.bsf-southsudan.org/sites/default/fi les/SHHS.pdf

[18] National High Blood Pressure Education Program. Seventh Complete report of Joint National Committee on Prevention, Detection, Evaluation and Treatment of High Blood Pressure. Available from: http://www.nhlbi.nih.gov/guidelines/hyper tension/jnc7full.pdf Accessed March 31, 2012.

[19] National Heart, Lung, and Blood Institute. Sixth Report of Joint National Committee on Prevention, Detection, Evaluation, and Treatment of High Blood Pressure. N0.98-4080. Available from: http://www.sld.cu/galerias/pdf/servicios/hta/ 6to._reporte_del_jnc_usa.pdf Accessed March 31, 2010.

[20] Univariate analysis From Wikipedia, the free encyclopedia. Available from: http://en.wikipedia.org/wiki/Univariate_a nalysis Accessed April 18, 2012.

[21] Bivariate analysis From Wikipedia, the free encyclopedia. Available from: http://en.wikipedia.org/wiki/Bivariate_an alysis

[22] World Health Organization. Health Research Methodology, A Guide for Training in Research Methods: 2nd ed. Regional Office for the Western Pacific Manila. 2001; 75-128. Available 
from: http://www.wpro.who.int/publications/docs/Hea lth_research_edited.pdf

[23] Fathalla MF. World Health Organization regional Mediterranean: Practical guide for Health Research. Series 30, Cairo; 2004. 52-113. Available from: http://whqlibdoc. who.int/emro/2004/9290 213639.pdf

[24] Evaluation of Cadmium, lead nicked and zinc status in biological samples of smokers and non smoker's hypertensive patients. Journal of Human Hypertension. 21maj 2009; 34-43. Available from: http://www. nature.com/jhh/Journal/v24/ni/fill /jhh20.939a.html Accessed February 1, 2010.

[25] WamalaJF, et al. Prevalence factors associated with Hypertension in Rukungiri District, Uganda-A Community-Based Study. African Health Sciences: Pub Med web site. 2009; 9(3): 153-160. Avalible from: http://www.ncbi.nlm.nih.gov/pmc/articles/PMC2887031/

[26] Lim TO, Morad Z. Hypertension Study Group Prevalence, Awareness, Treatment and Control of Hypertension in the Malaysian Adult Population: Results from the National Health and Morbidity Survey 1996. Singapore Med J. 2004; 45(1): 20-27. Available from: http://www.ncbi.nlm.nih.gov/pubmed/14976578

[27] Shirani S, et al. Awareness, treatment and control of hypertension, dyslipidemia and diabetes mellitus in an Iranian population: the IHHP study. Eastern Mediterranean Health Journal. 2009; 15(6). Avalible from: http://www. emro. who.int/emhj/1506/15_6_ 2009_1455_1463.pdf

[28] Agrawal Lt, et al. Prevalence and Determinants of Hypertension in a Rural Community. MJAFI. 2008; 64: 21-25. Available from: http: //www.mjafi.net/article/S0377-1237(08)80139-6/

[29] Tesfaye, et al. Population based prevalence of high blood pressure among adults in Addis Ababa. BioMed Central Ltd web site. 2009. Available from: http://www. biomedcentral.com/1471-2261/ 9/39 https://doi.org/10.1186/1471-2261-9-39
[30] Dongfeng GU, et al. Prevalence, Awareness, Treatment, and Control of Hypertension in China: American Heart Association. 2002; 920927. Available from: http://hyper. ahajournals .org/cgi/co ntent/full/40/6/920

[31] National Heart, Lung, and Blood Institute. National High Blood Pressure Educational Program, Primary Prevention of Hypertension: Clinical and Public Health Advisory from the National High Blood Pressure Education Program. 2002. Avalible from: http: //hp2010.nhlbihin.net/nhbpep_slds/jnc/jnc7txt.htm

[32] Vimala A, et al. The prevalence, risk factors and awareness of hypertension in an urban population of Kerala (South India), 2009. Saudi J Kidney Dis Transpl. 2010; 20(4): 685-689. Available from: http://www.sjkdt.org/text.asp?2009/20/4/685/53306

[33] Fotooh Al, et al. Prevalence of Hypertension in Young and Middle Aged Kuwaiti Citizens in Primary Health Care. Kuwait Medical Journal. 2005; 37(2): 116-119. Available from: http://www.kma.org. kw/kmj/Issues/june2007/Orginal $\% 20$ Article/64-03\%20Prevalence $\% 20$ of $\% 20$ Hyperte.pdf

[34] American Heart Association. Global Health-Hypertension in SubSaharan Africa: A Systematic Review. 2007; 1012-1018. Available from: http://hyper . ahajournals .org/content/50/6/1012. full

[35] Elzubier AG, et al. Drug compliance among hypertensive patients in Kassala, Eastern Sudan. Eastern Mediterranean Health Journal. Volume 6, Issue. 2000; 100-105. Available from: http://www.em ro.who.int/Publications/EMHJ/0601/13.htm

[36] Osman EM, et al. Clinico-Epidemiological Features of Hypertensive Subjects in Kassala Town, Eastern Sudan. Journal of Family and Community medicine, J Family Community Med. 2007; 14(2): 77-80. Available from: http://www.ncbi.nlm.nih.gov/pmc/a rticles/PMC3410150/ 